This is the author's final, peer-reviewed manuscript as accepted for publication. The publisher-formatted version may be available through the publisher's web site or your institution's library.

\title{
A consistency mapping for the effects on enzymatic hydrolysis sugar yield using two sugar yield definitions in cellulosic biofuel manufacturing
}

Meng Zhang, Xiaoxu Song, T. W. Deines, Z. J. Pei, and Donghai Wang

\section{How to cite this manuscript}

If you make reference to this version of the manuscript, use the following information:

Zhang, M., Song, X., Deines, T. W., Pei, Z. J., \& Wang, D. (2014). A consistency mapping for the effects on enzymatic hydrolysis sugar yield using two sugar yield definitions in cellulosic biofuel manufacturing. Retrieved from http://krex.ksu.edu

\section{Published Version Information}

Citation: Zhang, M., Song, X., Deines, T. W., Pei, Z. J., \& Wang, D. (2014). A consistency mapping for the effects on enzymatic hydrolysis sugar yield using two sugar yield definitions in cellulosic biofuel manufacturing. Renewable Energy, 62, 243-248.

Copyright: (c) 2013 Elsevier Ltd.

Digital Object Identifier (DOI): doi:10.1016/j.renene.2013.07.014

Publisher's Link: http://www.sciencedirect.com/science/article/pii/S0960148113003595

This item was retrieved from the K-State Research Exchange (K-REx), the institutional repository of Kansas State University. K-REx is available at http://krex.ksu.edu 


\title{
A consistency mapping for the effects on enzymatic hydrolysis sugar yield using two sugar yield definitions in cellulosic biofuel manufacturing
}

\author{
Meng Zhang ${ }^{a}$ Xiaoxu Song ${ }^{a}$ T.W. Deines ${ }^{a} Z_{\text {.J. Pei }}{ }^{\text {** }}$, and Donghai Wang \\ ${ }^{a}$ Department of Industrial and Manufacturing Systems Engineering, Kansas State \\ University, Manhattan, KS 66506, United States. \\ Email:meng@ksu.edu; xiaoxu@ksu.edu; tdeines@ksu.edu; zpei@ksu.edu \\ ${ }^{\mathrm{b}}$ Department of Biological and Agricultural Engineering, Kansas State University, \\ Manhattan, KS 66506, United States. \\ Email: dwang@ksu.edu
}

\section{Abstract}

Two different sugar yield definitions (cellulose-based and biomass-based) were used in reported studies investigating the relationship between biomass particle size and enzymatic hydrolysis sugar yield. It is noticed that these reported relationships are not consistent if sugar yield is defined differently. The literature does not contain any reports on the effects of sugar yield definition on the relationship between biomass particle size and enzymatic

\footnotetext{
*Corresponding author. Tel.: +1 785532 3436; fax: +1 7855323738 .
} 
hydrolysis sugar yield. This paper presents a consistency mapping to show under what conditions the relationships are consistent (or inconsistent) when these two definitions are used. The application of this mapping is illustrated via an experimental study with poplar wood biomass on the relationship between biomass particle size and enzymatic hydrolysis sugar yield using both sugar yield definitions. The application of this mapping is also illustrated via data reported in the literature. Not limited to particle size, this mapping is applicable to investigations of the relationships between a variety of parameters (biomass type, pretreatment condition, etc.) and enzymatic hydrolysis sugar yield.

\section{Keywords}

Biofuel; cellulosic biomass; enzymatic hydrolysis; particle size; sugar yield

\section{Introduction}

Biofuels have been recognized as promising alternatives to petroleum-based liquid transportation fuels [1-3]. Cellulosic biomass can be converted into biofuels through biochemical pathway. Before biochemical conversion, cellulosic biomass has to go through a size reduction step to make it easier to handle and to make the biofuel production process more efficient [4]. Cellulosic biomass biochemical conversion consists of two major processes. First, biomass particles produced by size reduction are depolymerized to fermentable sugars through pretreatment and enzymatic hydrolysis. Second, the 
fermentable sugars are converted into biofuel (ethanol) through fermentation [5].

Cellulosic biomass ethanol yield is highly dependent on the cellulose conversion rate during enzymatic hydrolysis [6]. Extensive research has been conducted to enhance the digestibility of cellulosic biomass in order to increase the enzymatic hydrolysis sugar yield [7,8]. Cellulosic biomass consists of mainly three different polymers, namely cellulose, hemicelluloses, and lignin. Cellulose is trapped in the shield formed by lignin and hemicelluloses $[7,9,10]$.

The size of particles produced after biomass size reduction (referred as particle size in the following content) is an important input parameter affecting enzymatic hydrolysis sugar yield $[11,12]$. The literature contains many studies investigating the relationship between particle size and sugar yield. However, the reported relationships are inconsistent. As shown in Table 1, many publications reported that smaller biomass particles had higher enzymatic hydrolysis sugar yield than larger biomass particles. However, there are also publications that did not support such a relationship.

It was found that two different sugar yield definitions were used in the related publications. One definition is cellulose-based sugar yield, and calculated as the percentage of cellulose in biomass converted to fermentable sugar (glucose) by enzymatic hydrolysis. 
The other definition is biomass-based sugar yield, and calculated as the ratio of the glucose produced by enzymatic hydrolysis to the initial dry weight of the biomass. In this paper, these two definitions are so called for the purpose of easy comparison and discussion. These concepts might be called differently elsewhere.

It is interesting to note that, when cellulose-based sugar yield definition was used, all (except one) publications reported the relationship that smaller biomass particles had a higher sugar yield. In the three publications that did not support such a relationship [19-21], biomass-based sugar yield definition was used. Furthermore, the literature does not contain any reports on the effects of sugar yield definition on the relationship between biomass particle size and enzymatic hydrolysis sugar yield.

This paper presents a consistency mapping to show under what conditions the relationships are consistent (or inconsistent) when these two definitions are used. The application of this mapping is then illustrated via an experimental study with poplar wood biomass the relationship between biomass particle size and enzymatic hydrolysis sugar yield using both sugar yield definitions. The application of this mapping is also illustrated via data reported in the literature. 


\section{Development of the consistency mapping}

\subsection{Two sugar yield definitions}

\subsubsection{Cellulose-based sugar yield}

Cellulose-based sugar yield was used to evaluate the efficiency of enzymatic hydrolysis. It is expressed in terms of the percentage of cellulose converted to fermentable sugar (glucose), and calculated by the following equation:

$$
\text { Cellulose - based sugar yield }(\%)=\frac{c \times V}{1.11 \times m \times C_{b}} \times 100 \%
$$

where $c$ is the concentration $(\mathrm{g} / \mathrm{L})$ of glucose in the hydrolysis slurry, $V(\mathrm{~L})$ is the total volume of the slurry, $m(\mathrm{~g})$ is the dry weight of the biomass loaded into the hydrolysis flask, and $C_{b}(\%)$ is the cellulose content in the biomass before hydrolysis. The factor 1.11 is the cellulose-to-glucose conversion factor, which reflects the weight gained in converting cellulose to glucose in hydrolysis.

\subsubsection{Biomass-based sugar yield}

Biomass-based sugar yield evaluates the glucose yield (g) per unit dry weight of biomass loaded into the hydrolysis process. It is calculated by the following equation:

$$
\text { Biomass - based sugar yield (g glucose/g dry biomass })=\frac{c \times V}{m}
$$

where $c$ is the concentration $(\mathrm{g} / \mathrm{L})$ of glucose in the hydrolysis slurry, $V(\mathrm{~L})$ is the total volume of the slurry, and $m(\mathrm{~g})$ is the dry weight of the biomass loaded into the hydrolysis 
process.

\subsection{Derivation of the consistency mapping}

The formulae for sugar yield calculation using the abovementioned two definitions involve two variables. One is glucose concentration $c(\mathrm{~g} / \mathrm{L})$ in two samples under comparison after hydrolysis $\left(c_{1}\right.$ and $\left.c_{2}\right)$, and the other is cellulose content $C_{b}(\%)$ in the two samples before hydrolysis $\left(C_{b 1}\right.$ and $\left.C_{b 2}\right)$. To simplify the derivation, the sample with a higher glucose concentration is subscripted as "1".

Whether the relationships between particle size and sugar yield using the two sugar yield definitions are consistent or not is determined by the relative values of $x$ and $y$. Where, " $x$ " is the difference in glucose concentration, and calculated as $x=\left[\left(c_{1}-c_{2}\right) / c_{2}\right] \times 100 \%, x>0$, and " $y$ " is the difference in cellulose content, and calculated as $y=\left[\left(C_{b 1}-C_{b 2}\right) / C_{b 2}\right] \times 100 \%, y>-1$. The statement that the relationships using these two definitions are consistent is equivalent to the following inequality:

$$
\left(\frac{c_{1} \times V_{1}}{1.11 \times m_{1} \times C_{b 1}} \times 100 \%-\frac{c_{2} \times V_{2}}{1.11 \times m_{2} \times C_{b 2}} \times 100 \%\right) \cdot\left(\frac{c_{1} \times V_{1}}{m_{1}}-\frac{c_{2} \times V_{2}}{m_{2}}\right)>0
$$

where, $m_{1}=m_{2}=m$, and $V_{1}=V_{2}=V$. Taking $c_{1}=(1+x) \cdot c_{2}$, and $C_{b 1}=(1+y) \cdot C_{b 2}$ into the inequality gives

$$
\left(\frac{(1+x) \cdot c_{2} \times V}{1.11 \times m \cdot(1+y) \cdot C_{b 2}} \times 100 \%-\frac{c_{2} \times V}{1.11 \times m \times C_{b 2}} \times 100 \%\right) \cdot\left(\frac{(1+x) \cdot c_{2} \times V}{m}-\frac{c_{2} \times V}{m}\right)>0
$$


Inequality (6) is reduced to

$$
\frac{V^{2} \times c_{2}^{2}}{1.11 \times m^{2} \times C_{b 2}} \cdot \frac{x \cdot(x-y)}{(1+y)}>0
$$

Because $x>0,1+y>0$, and others are positive constants, the solution to the inequality is $x>y$. To summarize, if $x>y$, the relationships are consistent; on the other hand, if $x \leq y$, the relationships are inconsistent. The above derivation is based on the scenario that $x>0$. In the special scenario that $x=0$, it is easy to find out that if $y=0$, the relationships are consistent; if $y \neq 0$, the relationships are inconsistent.

A consistency mapping $(\mathrm{x}>0)$, as shown in Fig. 1, is developed to show under what conditions the relationships between particle size and sugar yield using these two sugar yield definitions are consistent (or inconsistent).

\section{Experimental study to illustrate the application of the mapping}

\subsection{Material and methods}

\subsubsection{Material}

Poplar wood chips were purchased from Petco Animal Supplies, Inc. (Manhattan, KS, USA). The moisture content of the wood chips was $7.1 \%$. The wood chips were placed in sealed Ziploc ${ }^{\circledR}$ bags and stored at room temperature before size reduction by mills. Table 2 
lists the chemical composition of the wood chips.

\subsubsection{Biomass size reduction}

Two types of mills were used for size reduction of poplar wood chips: a knife mill (Model SM 2000, Retsch, GmbH, Haan, Germany) and a hammer mill (Model No. 5, Meadows Mills, Inc., North Wilkesboro, NC, USA). Sieves of two sieve sizes (with openings of 1 and $4 \mathrm{~mm}$ on the sieves) were used in both mills to produce poplar biomass particles with two levels $(-$ and + ) of particle size. Wood chips remained in the milling chamber until they were small enough to pass through the openings on the sieve. After milling, particles were collected and kept in sealed Ziploc ${ }^{\circledR}$ bags and stored in a refrigerator at $4^{\circ} \mathrm{C}$ until further processing. Table 3 lists the experimental conditions in biomass size reduction.

\subsubsection{Biomass extraction}

The purpose of biomass extraction is to remove extractives from wood particles produced by mills because these extractives could potentially interfere with subsequent analysis. The two-step extraction process was conducted by following National Renewable Energy Laboratory procedure (NREL/TP-510-42619) [22]. In the first step, distilled water was used (for $24 \mathrm{~h}$ ) to remove water-soluble extractives. In the second step, ethyl alcohol (190 proof) was used (for $24 \mathrm{~h}$ ) to remove alcohol-soluble extractives. After biomass extraction, wood particles were dried in an oven at $40^{\circ} \mathrm{C}$ for $24 \mathrm{~h}$ and stored in individual 
self-seal sample bags.

\subsubsection{Biomass pretreatment}

Dilute sulfuric acid pretreatment was employed in this study. Ten grams of extractive-free biomass particles and $200 \mathrm{~mL}$ of $2 \%(\mathrm{w} / \mathrm{v})$ sulfuric acid were loaded in the 600-mL vessel of a Parr pressure reactor (Model 4760A, Parr Instrument Co., Moline, IL, USA), and treated at $140^{\circ} \mathrm{C}$ for $30 \mathrm{~min}$.

The pretreated biomass particles were washed with hot distilled water using a centrifugal (Model Marathon 2100, Thermo International Equipment Co., Needham, MA, USA) to remove dissolved sugars, acid residues, and inhibitors (substances that would decrease enzymes' ability to depolymerize cellulose to glucose [23]) formed during pretreatment. The rotation speed of the centrifugal was 4,000 rpm. Each biomass sample was washed three times, and each time lasted for $15 \mathrm{~min}$. The solid biomass after

centrifugal was carefully collected. For each test condition, a small portion of the collected solid biomass was used for chemical composition analysis, and the rest was used for subsequent enzymatic hydrolysis.

\subsubsection{Enzymatic hydrolysis}

Enzymatic hydrolysis was carried out in eight $125-\mathrm{mL}$ flasks in a water bath shaker (Model C76, New Brunswick Scientific, Edison, NJ, USA) with agitation speed of $110 \mathrm{rpm}$ 
at $50^{\circ} \mathrm{C}$ for $48 \mathrm{~h}$. There were two flasks containing biomass particles collected under each of the four size reduction conditions. Each flask contained $50 \mathrm{~mL}$ of hydrolysis slurry. The slurry consisted of $5 \%(\mathrm{w} / \mathrm{v})$ biomass on dry weight base, sodium acetate buffer $(50 \mathrm{mM}$, $\mathrm{pH}=4.8)$, and $0.02 \%(\mathrm{w} / \mathrm{v})$ sodium azide to prevent microbial growth during hydrolysis. Accellerase $1500^{\mathrm{TM}}$ enzyme complex (Danisco USA, Inc., Rochester, NY, USA) was used. The enzyme loaded was $1 \mathrm{~mL}$ for each gram of dry biomass.

After hydrolysis for $48 \mathrm{~h}, 0.1 \mathrm{~mL}$ of the hydrolysis slurry was withdrawn from each flask, and mixed with $0.9 \mathrm{~mL}$ of double distilled water in a $1.5-\mathrm{mL}$ micro-centrifuge tube. The caped tubes were placed into boiling water for 15 min to deactivate the enzyme. Afterwards, the tubes were centrifuged at $10,000 \mathrm{rpm}$ for $15 \mathrm{~min}$ to separate supernatant liquid from solid biomass residues using a micro-centrifuge (Model RS-102, Revolutionary Science, Shafer, MN, USA). Supernatant liquid from each tube was filtered through a 0.2- $\mu \mathrm{m}$ hydrophilic PTFE syringe filter (EMD Millipore, Billerica, MA, USA). Filtered supernatant liquid was kept in $1.5-\mathrm{mL}$ autosampler vials at $4^{\circ} \mathrm{C}$ in a refrigerator before sugar concentration measurement.

\subsection{Measurement procedures}

\subsubsection{Moisture content and dry weight}

Biomass moisture content was measured by following National Renewable Energy 
Laboratory procedure (NREL/TP-510-42621) [24]. About $2.5 \mathrm{~g}$ of biomass was placed in an aluminum weighing dish and dried in an oven at $105^{\circ} \mathrm{C}$ for $24 \mathrm{~h}$. The loss in weight of the biomass after oven drying was recorded. Moisture content was calculated as follows:

$$
\text { Moisture content }(M C)(\%)=\frac{\text { Loss in weight }}{\text { Weight of biomass before drying }} \times 100 \%
$$

Knowing the moisture content, dry weight could be calculated as follows:

$$
\text { Dry weight }(\mathrm{g})=(1-\mathrm{MC}) \times \text { weightof biomasswith moisture }
$$

Biomass weight reported in this study is dry weight.

\subsubsection{Chemical composition}

The chemical composition of biomass (wood chips before size reduction or biomass particles collected after pretreatment) was measured by following the National Renewable Energy Laboratory procedure (NREL/TP-510-42618) [25]. Two duplications for each test

condition were employed. Structural carbohydrates in biomass were reported as the percentages of cellulose and hemicellulose. Lignin, the major non-carbohydrate component, was reported as the percentage of the sum of acid-insoluble and acid-soluble lignin. The percentage of ash content was also reported.

\subsubsection{Sugar concentration}

Sugar concentration was measured using high performance liquid chromatography (HPLC). The HPLC (Shimadzu, Kyoto, Japan) system was equipped with an RPM-monosaccharide column $(300 \times 7.8 \mathrm{~mm}$; Phenomenex, Torrence, CA, USA $)$ and a 
refractive index detector (RID-10A, Shimadzu, Kyoto, Japan). The mobile phase was 0.6 $\mathrm{mL} / \mathrm{min}$ of degassed double-distilled water, and the column oven temperature was $80^{\circ} \mathrm{C}$.

\subsection{Experimental results}

\subsubsection{Cellulose-based sugar yield}

In order to calculate cellulose-based sugar yield, the content of cellulose in biomass samples before hydrolysis were acquired through chemical composition analysis and are listed in Table 4 together with other chemical components. It can be seen that cellulose contents for the two particle size levels are approximately the same.

The relationship between particle size and cellulose-based sugar yield is shown in Fig. 2. Smaller biomass particles had a higher sugar yield than larger particles, for both knife milling and hammer milling methods. This can be interpreted as that cellulose in smaller biomass particles were more efficiently hydrolyzed into glucose by enzymes in hydrolysis.

Mooney et al. [13] hydrolyzed Douglas fir woody biomass of two particle size levels. Their results showed that cellulose-based sugar yield of smaller particles was $24 \%$ higher than that of larger particles after 72-h hydrolysis (Fig. 3). The same trend was also reported by Zhu et al. [17] using a shorter hydrolysis time (12 h) to convert spruce woody biomass of four particle size levels (Fig. 4). This trend was also reported for herbaceous biomass. As 
an example, Zeng et al. [15] milled corn stover and separated milled particles into two particle size levels. They found that when using cellulose-based sugar yield definition, smaller particles produced higher yield (Fig. 5).

\subsubsection{Biomass-based sugar yield}

Figure 6 shows the relationship between particle size and biomass-based sugar yield. For both knife milling and hammer milling methods, smaller biomass particles have a higher sugar yield than larger biomass particles. Dasari and Benson [16] reported a similar trend for red-oak (Fig. 7). Smaller particles had a higher sugar yield than larger particles.

Not all related publications support this relationship. Zhang et al. [21] found that larger wheat straw particles milled using a 2-mm sieve had higher cellulose-based sugar yield than smaller particles milled using a 1-mm sieve (Fig. 8). It is noted that, in this work, before pretreatment, a pelleting process was employed to agglomerate milled biomass particles into pellets. Kaar and Holtzapple [20] found that cellulose-based sugar yield of smaller corn stover particles was lower than that of larger particles (Fig. 9). Chang et al. [19] found that, though switchgrass particles with particle size of $0.40-0.84 \mathrm{~mm}$ had $18 \%$ higher cellulose-based sugar yield than particles with particle size of $0.84-2 \mathrm{~mm}$, reducing particle size below $0.4 \mathrm{~mm}$ did not increase sugar yield (Fig. 10). 


\section{Application of the consistency mapping}

\subsection{Illustration using data from the experimental study}

In the present experimental study, the required values to apply the consistency mapping are calculated as $x=6.84 \%$ and $y=0.24 \%$ for the small and large particles produced by knife milling; $x=12.37 \%$ and $y=1.40 \%$ for the small and large particles produced by hammer milling (values were calculated using the means of the two duplicated tests). Since $x>y$, the relationships between particle size and sugar yield using the two sugar yield definitions are consistent.

\subsection{Illustration using data from study reported in the literature}

Applications of the consistency mapping can also be illustrated using the data published in the literature. A study conducted by Ballesteros et al. [26] was employed as an example. The authors studied the sugar yield of softwood biomass of two levels of particle size. The reported sugar yield was cellulose-based. From the data listed in Table 5, the values needed to apply the consistency mapping are calculated as $\mathrm{x}=6.16 \%$ and $\mathrm{y}=$ $12.79 \%$. Since $\mathrm{x}<\mathrm{y}$, the relationships between particle size and sugar yield using two sugar yield definitions are inconsistent. 


\section{Conclusions}

This paper develops a consistency mapping for the effects on enzymatic hydrolysis sugar yield using two sugar yield definitions. The application of this mapping is illustrated via an experimental study with poplar wood biomass on the relationship between biomass particle size and enzymatic hydrolysis sugar yield. Under the experimental conditions in this study, smaller particles had a higher sugar yield. This relationship remained consistent using both sugar yield definitions. This mapping is not limited to investigations on the relationship between particle size and sugar yield. It is applicable to studying relationships between a variety of parameters (such as biomass type, pretreatment condition, etc.) and sugar yield.

\section{Acknowledgements}

This study is supported by the U.S. National Science Foundation through award 0970112. The authors gratefully extend their acknowledgement to China Scholarship Council for the financial support to the first two authors. The authors gratefully acknowledge Dr. Feng Xu and Mr. Ke Zhang in the Department of Biological and Agricultural Engineering at Kansas State University for their assistance in measurements.

\section{References}

1. Energy Information Administration, Annual energy review 2010 
DOE/EIA-0384(2010),

http://205.254.135.24/totalenergy/data/annual/pdf/aer.pdf.

2. R.D. Perlack, L.L. Wright, A.F. Turhollow, R.L. Graham, B.J. Stokes, D.C. Erbach, Biomass as feedstocks for a bioenergy and byproducts industry: the technical feasibility of a billion-ton annual supply, DOE/GO-102005-2135, Oak Ridge National Laboratory, 2005 , http://feedstockreview.ornl.gov/pdf/billion_ton_vision.pdf.

3. R.D. Perlack, B.J. Stokes, U.S. billion-ton update: biomass supply for a bioenergy and bioproducts industry, ORNL/TM-2011/224, Oak Ridge National Laboratory, 2011, http://www1.eere.energy.gov/biomass/pdfs/billion_ton_update.pdf.

4. Department of Energy, The production of ethanol from cellulosic biomass, 2012, http://cta.ornl.gov/bedb/biofuels/ethanol/The_Production_of_Ethanol_from_Cellulo sic_Biomass-Figure.xls.

5. C.M. Drapcho, N.P. Nhuan, T.H. Walker, Biofuels engineering process technology, McGraw-Hill Companies, Inc., USA, 2008.

6. A. Pandey, C. Larroche, S.C. Ricke, C. Dussap, E. Gnansounou, Biofuels: alternative feedstocks and conversion processes, Academic Press, USA, 2011.

7. Y. Zheng, Z. Pan, R. Zhang, Overview of biomass pretreatment for cellulosic ethanol production, Int. J. Agric. Biol. Eng. 2 (2009) 51-68.

8. A.T.W.M. Hendriks, G. Zeeman, Pretreatments to enhance the digestibility of 
lignocellulosic biomass, Bioresour. Technol. 100 (2009) 10-18.

9. D. Fengel, G. Wegener, Wood: chemistry, ultrastructure, reactions, Walter De Gruyter Inc, Germany, 1984.

10. N. Mosier, C. Wyman, B. Dale, R. Elander, Y.Y. Lee, M.T. Holtzapple, M. Ladisch, Features of promising technologies for pretreatment of lignocellulosic biomass. Bioresour. Technol. 96 (2005) 673-686.

11. B.C. Vidal Jr., B.S. Dien, K.C. Ting, V. Singh, Influence of feedstock particle size on lignocellulose conversion - a review, Appl. Biochem. Biotechnol. 164 (2011) $1405-1421$.

12. C.A. Mooney, S.D. Mansfield, M.G. Touhy, J.N. Saddler, The effect of initial pore volume and lignin content on the enzymatic hydrolysis of softwoods, Bioresour. Technol. 64 (1998) 113-119.

13. C.A. Mooney, S.D. Mansfield, R.P. Beatson, J.N. Saddler, The effect of fiber characteristics on hydrolysis and cellulase accessibility to softwood substrates, Enzyme Microb. Tech. 25 (1999) 644-650.

14. U. Mais, A.R. Esteghlalian, J.N. Saddler, S.D. Mansfield, Enhancing the enzymatic hydrolysis of cellulosic materials using simultaneous ball milling, Appl. Biochem. Biotechnol. 98-100 (2002) 815-832.

15. M. Zeng, N.S. Mosier, C. Huang, D.M. Sherman, M.R. Ladisch, Microscopic examination of changes of plant cell structure in corn stover due to hot water 
pretreatment and enzymatic hydrolysis, Biotechnol. Bioeng. 97 (2007) 265-278.

16. R.K. Dasari, R.E. Berson, The effect of particle size on hydrolysis reaction rates and rheological properties in cellulosic slurries, Appl. Biochem. Biotechnol. 137 (2007) 289-299.

17. J.Y. Zhu, G.S.Wang, X.J. Pan, R. Gleisner, Specific surface to evaluate the efficiencies of milling and pretreatment of wood for enzymatic saccharification, Chem. Eng. Sci. 64 (2009) 474-485.

18. W. Zhu, J.Y. Zhu, G.S. Wang, R. Gleisner, X.J. Pan, On energy consumption for size-reduction and yields from subsequent enzymatic saccharification of pretreated lodgepole pine, Bioresour. Technol. 101 (2010) 2782-2792.

19. V.S. Chang, B. Burr, M.T. Holtzapple, Lime pretreatment of switchgrass, Appl. Biochem. Biotechnol. 63-65 (1997) 3-19.

20. W.E. Kaar, M.T. Holtzapple, Using lime pretreatment to facilitate the enzymatic hydrolysis of corn stover, Biomass Bioenerg. 18 (2000) 189-199.

21. P.F. Zhang, T.W. Deines, Z.J. Pei, D. Nottingham, D.H. Wang, X.R. Wu, Ultrasonic vibration-assisted pelleting of biomass: a designed experimental investigation on pellet quality and sugar yield, Proceedings of the 2010 ASME International Conference on Manufacturing Science and Engineering, Erie, PA, October 12-15.

22. A. Sluiter, R. Ruiz, C. Scarlata, J. Sluiter, D. Templeton, Determination of extractives in biomass, NREL/TP-510-42619, 2008, 
http://www.nrel.gov/biomass/pdfs/42619.pdf.

23. K.C. Mary, S.O. Farrell, Biochemistry, seventh edition, Mary Finch Publisher, USA, 2011.

24. A. Sluiter, B. Hames, D. Hyman, C. Payne, R. Ruiz, C. Scarlata, J. Sluiter, D. Templeton, J. Wolfe, Determination of total solids in biomass and total dissolved solids in liquid process samples, NREL/TP-510-42621, 2008, http://www.nrel.gov/biomass/pdfs/42621.pdf.

25. A. Sluiter, B. Hames, R. Ruiz, C. Scarlata, J. Sluiter, D. Templeton, D. Crocker, Determination of structural carbohydrates and lignin in biomass, NREL/TP-510-42618, 2008, http://www.nrel.gov/biomass/pdfs/42618.pdf.

26. I. Ballesteros, J.M. Oliva, A.A. Navarro, A. Gonzalez, J. Carrasco, M. Ballesteros, Effect of chip size on steam explosion pretreatment of softwood, Appl. Biochem. Biotechnol. 84-86 (2000) 97-110. 


\section{Figure caption}

Fig. 1 Consistency mapping

Fig. 2 Relationship between particle size and cellulose-based sugar yield in this study

Fig. 3 Relationship between particle size and cellulose-based sugar yield reported by Mooney et al. [13]

Fig. 4 Relationship between particle size and cellulose-based sugar yield reported by Zhu et al. [17]

Fig. 5 Relationship between particle size and cellulose-based sugar yield reported by Zeng et al. [15]

Fig. 6 Relationship between particle size and biomass-based sugar yield in this study

Fig. 7 Relationship between particle size and biomass-based sugar yield reported by Dasari and Benson [16]

Fig. 8 Relationship between particle size and biomass-based sugar yield reported by Zhang et al. [21]

Fig. 9 Relationship between particle size and biomass-based sugar yield reported by Kaar and Holtzapple [20]

Fig. 10 Relationship between particle size and biomass-based sugar yield reported by Chang et al. [19] 


\section{Figures}

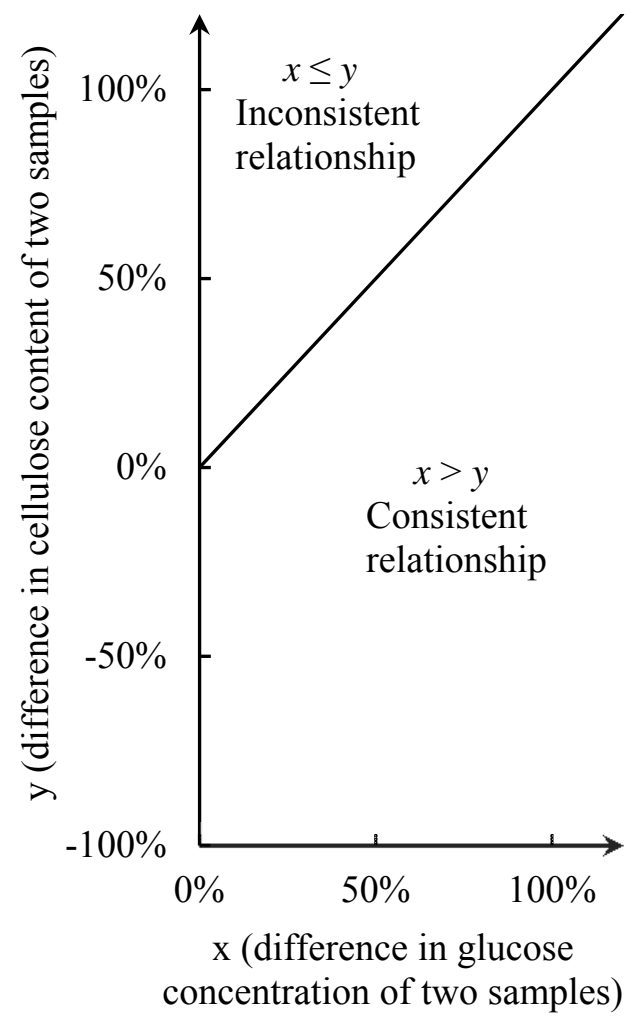

Fig. 1

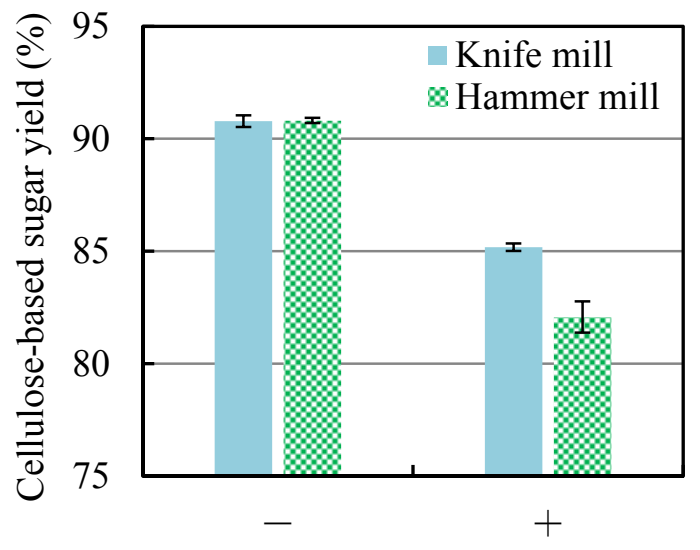

Particle size level

Hydrolysis time $=48 \mathrm{~h}$ 
Fig. 2

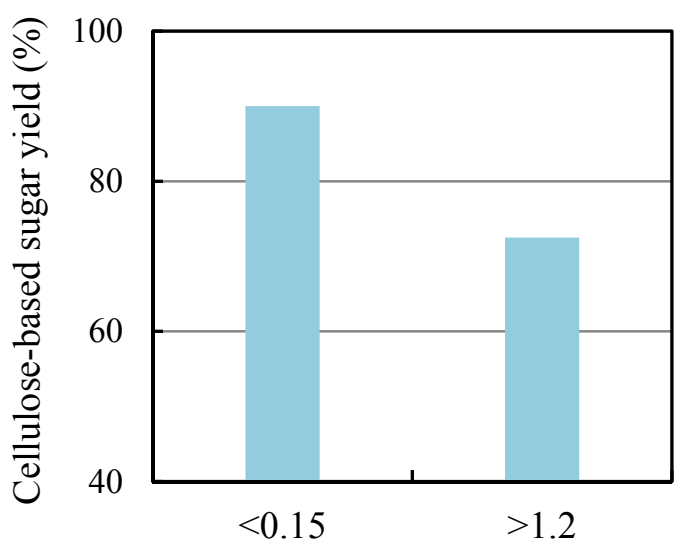

Particle size level (mm)

Hydrolysis time $=72 \mathrm{~h}$

Fig. 3

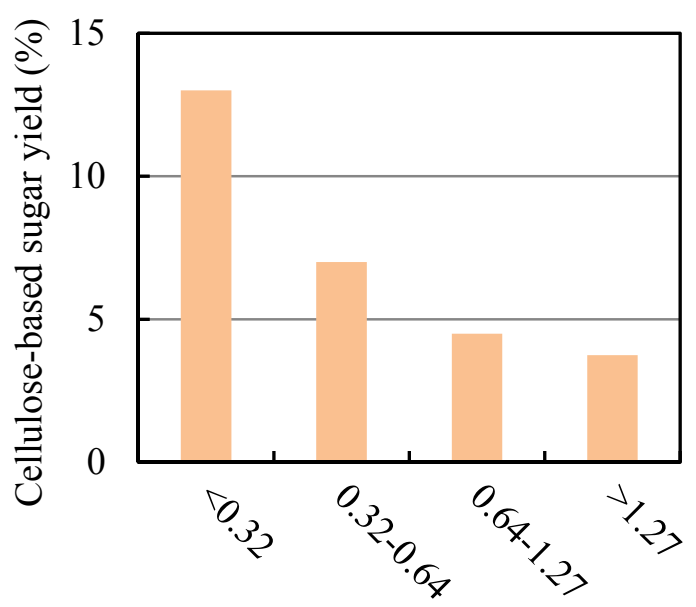

Particle size level (mm)

Hydrolysis time $=12 \mathrm{~h}$

Fig. 4 


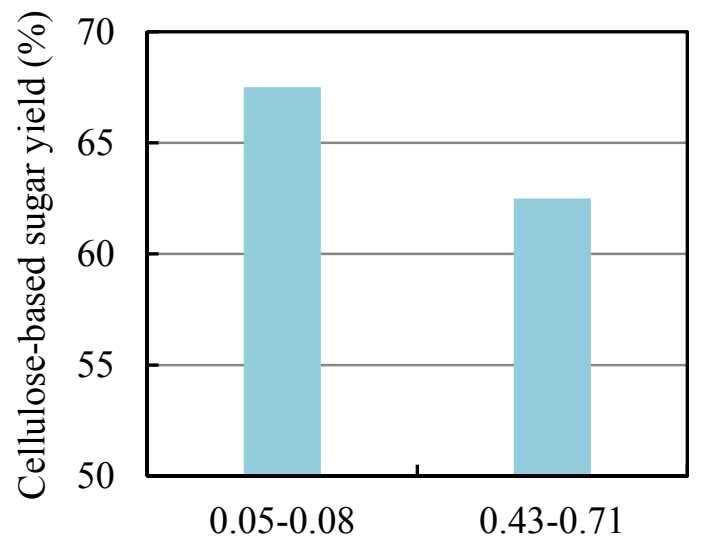

Particle size level (mm)

Hydrolysis time $=72 \mathrm{~h}$

Fig. 5

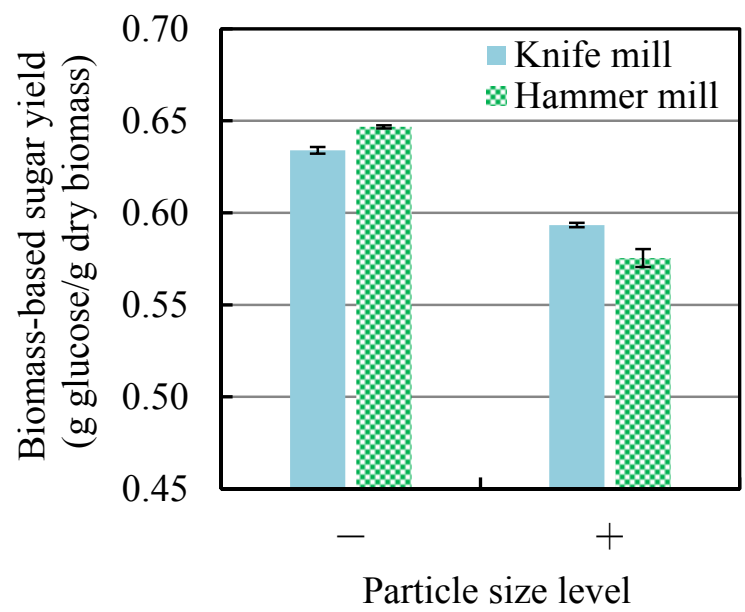

Hydrolysis time $=48 \mathrm{~h}$

Fig. 6 


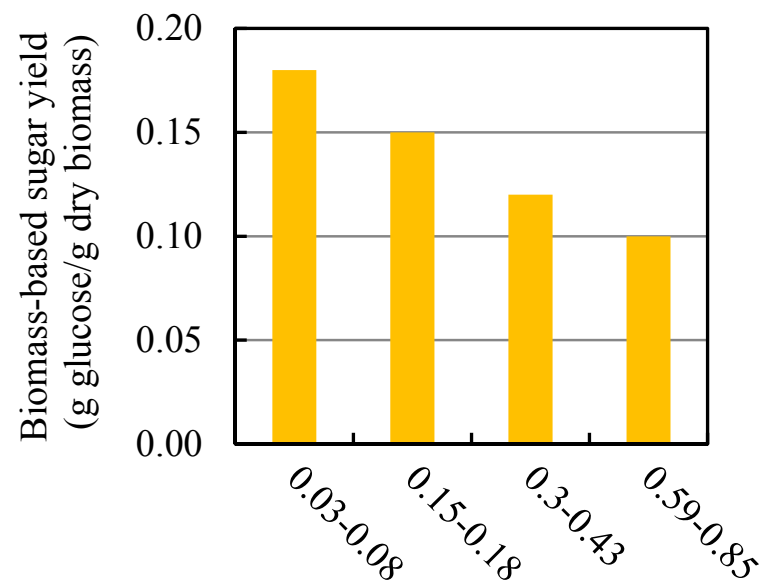

Particle size level (mm)

Hydrolysis time $=72 \mathrm{~h}$

Fig. 7

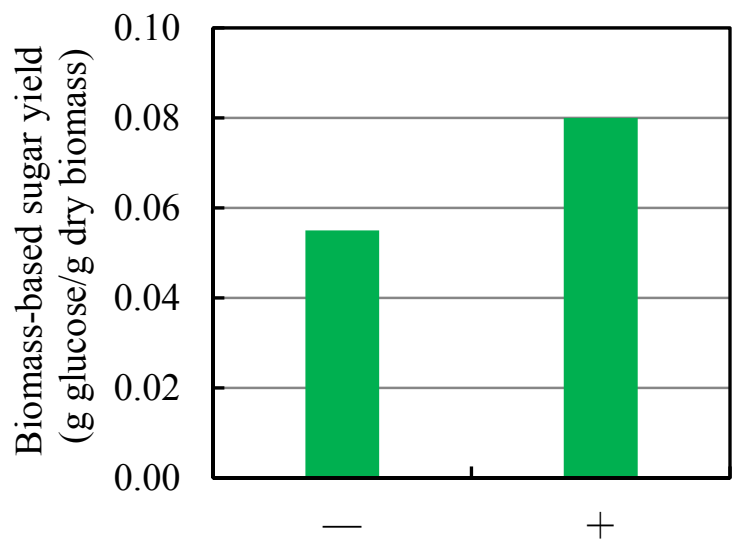

Particle size level

Hydrolysis time $=48 \mathrm{~h}$

Fig. 8 


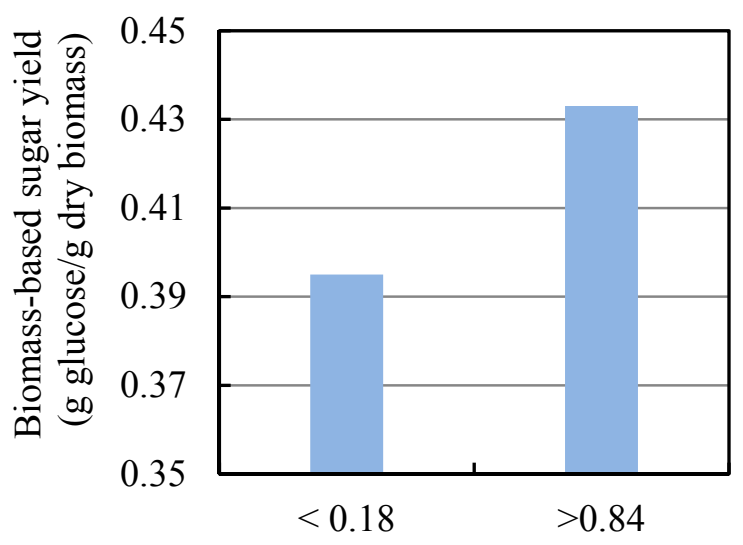

Particle size level (mm)

Hydrolysis time $=72 \mathrm{~h}$

Fig. 9

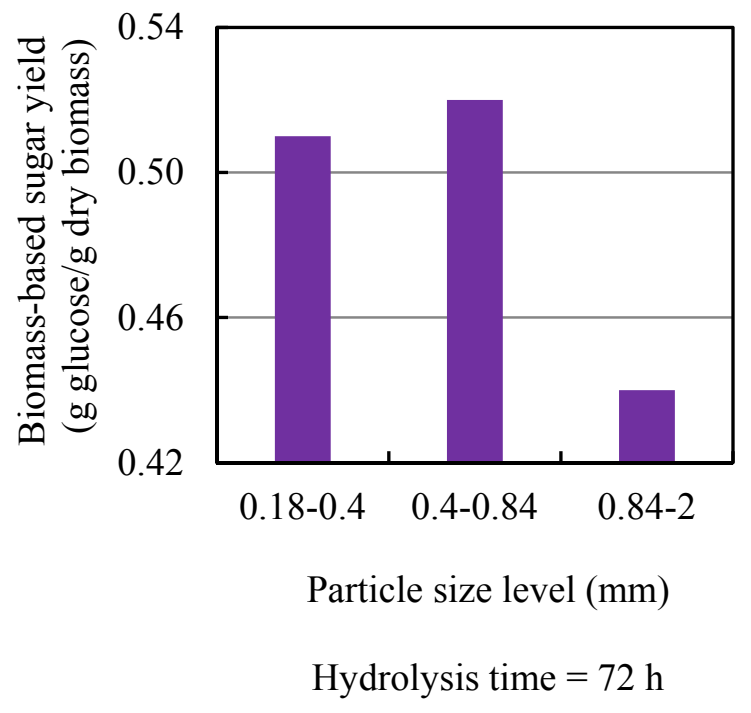

Fig. 10 


\section{Tables}

Table 1 Reported relationship between particle size and sugar yield

\begin{tabular}{cccc}
\hline $\begin{array}{c}\text { Biomass } \\
\text { material }\end{array}$ & $\begin{array}{c}\text { Smaller particles } \\
\text { produced higher } \\
\text { sugar yield }\end{array}$ & $\begin{array}{c}\text { Sugar yield } \\
\text { definition }\end{array}$ & Reference \\
\hline Douglas fir & Yes & Cellulose based & {$[13]$} \\
Douglas fir & Yes & Cellulose based & {$[14]$} \\
Corn stover & Yes & Cellulose based & {$[15]$} \\
Red oak & Yes & Biomass based & {$[16]$} \\
Spruce wood & Yes & Cellulose based & {$[17]$} \\
Lodgepole pine & Yes & Cellulose based & {$[18]$} \\
Switchgrass & No & Biomass based & {$[19]$} \\
Corn stover & No & Biomass based & {$[20]$} \\
Wheat straw & No & Biomass based & {$[21]$} \\
\hline
\end{tabular}


Table 2 Chemical composition of poplar wood chips

\begin{tabular}{cc}
\hline Component & Percentage on dry weight basis \\
\hline Cellulose & $41.1 \pm 0.4$ \\
Hemicellulose & $22.9 \pm 0.3$ \\
Lignin & $24.0 \pm 0.7$ \\
Ash & $2.9 \pm 0.1$ \\
\hline
\end{tabular}


Table 3 Particle size levels and size reduction conditions Condition No. Particle size level Mill type Sieve size (mm)

\begin{tabular}{llll}
1 & - & Knife & 1 \\
2 & + & Knife & 4 \\
3 & - & Hammer & 1 \\
4 & + & Hammer & 4 \\
\hline
\end{tabular}


Table 4 Chemical composition (percentage on dry weight basis) for biomass particles before hydrolysis

\begin{tabular}{ccccccc}
\hline $\begin{array}{c}\text { Condition } \\
\text { No. }\end{array}$ & $\begin{array}{c}\text { Particle } \\
\text { size level }\end{array}$ & $\begin{array}{c}\text { Mill } \\
\text { type }\end{array}$ & Cellulose & Hemicellulose & Lignin & Ash \\
\hline 1 & - & Knife & $62.9 \pm 1.1$ & $4.2 \pm 0.1$ & $30.7 \pm 0.2$ & $1.6 \pm 0.1$ \\
2 & + & Knife & $62.8 \pm 0.1$ & $4.5 \pm 0.1$ & $31.0 \pm 0.2$ & $1.6 \pm 0.2$ \\
3 & - & Hammer & $64.1 \pm 0.1$ & $4.6 \pm 0.1$ & $29.3 \pm 0.1$ & $1.6 \pm 0.1$ \\
4 & + & Hammer & $63.2 \pm 0.7$ & $4.4 \pm 0.1$ & $31.9 \pm 0.7$ & $1.3 \pm 0.1$ \\
\hline
\end{tabular}


Table 5 Data reported by Ballesteros et al. [26]

\begin{tabular}{ccc}
\hline & Small particle size & Large particle size \\
\hline Particle size level $(\mathrm{mm})$ & $2-5$ & $5-8$ \\
Cellulose-based sugar yield (\%) & 36 & 34 \\
Biomass-based sugar yield (g glucose/g dry & 0.14 & 0.15 \\
biomass) $^{\mathrm{a}}$ & 2.76 & 2.93 \\
Sugar concentration $(\mathrm{g} / \mathrm{L})^{\mathrm{a}}$ & 34.4 & 38.8 \\
Cellulose content $(\%)$ & &
\end{tabular}

${ }^{\mathrm{a}}$ Data obtained through calculation based on data provided by Ballesteros et al. [26] 